$12-2019$

\title{
Intravenous dexamethasone along with caudal block improves analgesic efficacy following day-case inguinal hernia repair in children: A randomized controlled trial
}

Amjad Nadeem

KRL Hospital, Islamabad , Pakistan

Aliya Ahmed

Aga Khan University, aliya.ahmed@aku.edu

Follow this and additional works at: https://ecommons.aku.edu/pakistan_fhs_mc_anaesth

Part of the Diseases Commons, and the Pediatrics Commons

\section{Recommended Citation}

Nadeem, A., Ahmed, A. (2019). Intravenous dexamethasone along with caudal block improves analgesic efficacy following day-case inguinal hernia repair in children: A randomized controlled trial. JPMA. The Journal of the Pakistan Medical Association, 69(12), 1785-1789.

Available at: https://ecommons.aku.edu/pakistan_fhs_mc_anaesth/384 
ORIGINAL ARTICLE

\title{
Intravenous dexamethasone along with caudal block improves analgesic efficacy following day-case inguinal hernia repair in children: A randomized controlled trial
}

Amjad Nadeem, ${ }^{1}$ Aliya Ahmed²

\begin{abstract}
Objective: To assess the effectiveness of intravenous dexamethasone along with caudal block in improving analgesia following inguinal hernia repair in children.

Methods: The double-blind randomised controlled trial was conducted over a 6-month period from June 01, 2016 to November 30, 2016 at the Aga Khan University Hospital, Karachi, and comprised patients aged 1-5 years, scheduled for elective inguinal hernia repair. The subjects were randomised into two groups using the sealed envelope technique. Group D patients received $0.5 \mathrm{mg} / \mathrm{kg}$ dexamethasone intravenous in $5 \mathrm{ml}$, and group $\mathrm{P}$ was given placebo ( $5 \mathrm{ml} 0.9 \%$ saline). Assessment of postoperative pain was made through the faces, legs, activity, cry and consolability tool at 30 minutes and hourly for 4 hours. Rescue analgesia was given at pain score 3 or more with intravenous pethidine $0.5 \mathrm{mg} / \mathrm{kg}$. SPSS 19 was used for data analysis.

Results: Of the 64 patients, there were 55(85.9\%) boys and 9(14.1\%) girls. The overall mean age was $29.8 \pm 13.8$ months. The mean postoperative pain score was significantly higher in group $P(p<0.05)$. At 30 minutes and two hours postoperatively, need for analgesia was also significantly higher in group $P(p<0.05)$.

Conclusion: In paediatric day-care inguinal hernia repair, dexamethasone could be used effectively for improving pain relief.

Keywords: Paediatric inguinal hernia, Dexamethasone, Anaesthesia, Analgesia. (JPMA 69: 1785; 2019)

DOI:10.5455/JPMA.301035
\end{abstract}

\section{Introduction}

Adequate analgesia with minimal side effects is an important requirement for surgeries performed on a daycase basis. ${ }^{1}$ Opioids provide reliable postoperative analgesia, but have limitations in day-case surgeries due to their side effects such as delayed awakening, drowsiness, nausea, vomiting, etc. ${ }^{2}$

The current strategy of multimodal analgesia for postoperative pain management is recommended to achieve effective pain relief while reducing opioid-related adverse effects. ${ }^{3}$ It is known that general anaesthesia combined with regional block provides effective postoperative analgesia and reduces intraoperative anaesthetic requirement, resulting in a quicker recovery. 4 Caudal block along with general anaesthesia is a popular technique for providing effective intra and postoperative analgesia for infra-umbilical surgeries in paediatric patients. ${ }^{5}$

An important contribution to the origin of surgical pain is made by the acute inflammation caused by tissue

1Department of Anaesthesiology, KRL Hospital, Islamabad, 2Department of Anaesthesiology, Aga Khan University, Karachi, Pakistan.

Correspondence: Aliya Ahmed. Email: aliya.ahmed@aku.edu injury. ${ }^{6}$ Dexamethasone is a corticosteroid with potent anti-inflammatory effect which might contribute to postoperative analgesia. An intraoperative intravenous (IV) injection of $8 \mathrm{mg}$ dexamethasone has been shown to be effective in reducing postoperative analgesic requirements in dental and thyroid surgeries in adults. 7,8

In one study, children receiving IV dexamethasone with caudal block were found to need less rescue analgesia compared to the control group (7.9\% vs. $38.5 \%)$ following orchidopexy. ${ }^{9}$ Another study showed similar results when caudal block with levobupivacaine was used with IV dexamethasone in children. ${ }^{10}$ In another randomised controlled trial, single-dose dexamethasone in combination with penile block decreased postoperative analgesic requirement. ${ }^{11}$ Caudal block with bupivacaine has duration of action of around 03 hours.12,13 The current study was planned to determine the effectiveness of IV dexamethasone along with caudal analgesia in improving pain relief in children undergoing inguinal hernia repair.

\section{Patients and Methods}

The double-blind randomised controlled trial (RCT) was conducted over a 6-month period from June 01, 2016 to November 30, 2016 at the Aga Khan University Hospital, 
Karachi. After approval from the institutional ethics committee, the sample size was calculated on the basis of a study ${ }^{14}$ in which fewer patients receiving dexamethasone along with caudal block needed additional analgesia compared to those receiving caudal analgesia alone (7.9\% vs. $38.5 \%)$ following paediatric orchidopexy. The sample size was calculated for achieving $90 \%$ power at significance level of $5 \%$.

All paediatric patients aged 1-5 years, American Society of Anaesthesiologists (ASA) class 1 and 2, scheduled for elective inguinal hernia repair and who were to receive caudal block were included. Patients with congenital heart disease, deranged hepatic or renal function, haemorrhagic diathesis, known allergy to the study drug, obesity and local anatomic abnormalities were excluded. Patients in whom there was failure to perform block or who required intraoperative narcotics were also excluded.

In the evening, the operating list for the following day were examined by the primary investigator to note down the paediatric patients booked for inguinal hernia repair. Patients meeting the inclusion criteria were selected and written informed consent was taken from the parents. Patients received midazolam $0.5 \mathrm{mg} / \mathrm{kg}$ orally up to maximum of $7.5 \mathrm{mg}$ as premedication an hour before surgery. Random allocation was carried out using the sealed envelope technique. Each patient was allocated to one of the two groups. Patients in group D were given $0.5 \mathrm{mg} / \mathrm{kg}$ dexamethasone (maximum of $10 \mathrm{mg}$ ) made up to $5 \mathrm{ml}$ by adding $0.9 \%$ saline and labelled the 'study drug', while patients in group P were administered $5 \mathrm{ml}$ of $0.9 \%$ saline, also labelled the 'study drug'. All the drugs were made and supplied by an anaesthetist who was not involved in data collection. Anaesthetic management was conducted by the primary anaesthetist assigned to the operating room (OR) and blinded to the study groups.

In the OR, standard monitoring was applied and after obtaining baseline vitals, sevoflurane $5-8 \%$ in oxygen was administered for the induction of anaesthesia, and IV access was secured. A laryngeal mask airway (LMA) was inserted and caudal block was performed in the lateral position with bupivacaine $0.25 \% \quad 1 \mathrm{ml} / \mathrm{kg}$ (maximum $20 \mathrm{ml}$ ). The patient was then administered drug according to the group. Primary anaesthetist responsible for the OR, with experience of more than 2 years, performed the caudal block. The patient breathed spontaneously during maintenance of anaesthesia with sevoflurane in $50 \%$ oxygen and nitrous oxide. Surgery was started by consultant paediatric surgeon 15 minutes after the caudal block was performed. More than $20 \%$ variability in vitals was considered to be ineffective caudal block. IV pethidine $0.5 \mathrm{mg} / \mathrm{kg}$ was given to the patients if the caudal block was found ineffective. On completion of surgery, patient was awakened and taken to post-anaesthesia care unit (PACU). One of the researchers, blinded to the group allocation, collected data in PACU and day-care unit. Pain was assessed according to the faces, legs, activity, cry and consolability (FLACC) score of 0-10. Assessment of pain was performed at 30 minutes, one hour, two hours, three hours and four hours after the end of the procedure. Rescue analgesia, if needed, was given at pain score 3 or more with IV pethidine bolus of $0.5 \mathrm{mg} / \mathrm{kg}$. Final pain assessment was done at four hours postoperatively and analgesia was considered effective if no rescue analgesia was required. All patients were discharged within 6-8 hours of the end of the surgical procedure.

SPSS 19 was used for statistical analysis. Mean and standard deviation (SD) were calculated for quantitative elements, such as age, height, weight and duration of surgery, while frequencies and percentages were computed for categorical variables, including gender and analgesic efficacy. Independent sample t-test for normal data and Mann-Whitney test for the rest were applied to compare mean and median values between the groups for age and duration of surgery respectively. Difference in analgesic efficacy between the groups was compared using chi-square test. $\mathrm{P}<0.05$ was considered significant.

\section{Results}

Of the 64 patients, there were 55(85.9\%) boys and $9(14.1 \%)$ girls. The overall mean age was $29.8 \pm 13.8$ months. Gender, age, weight, height and duration of surgery were not significantly different between the groups ( $p>0.05)$ (Table-1).

On arrival in PACU, group $\mathrm{P}$ patients had significantly

Table-1: Comparison of demographic characteristics of patients between groups.

\begin{tabular}{lccc}
\hline Variables & $\begin{array}{c}\text { Group D } \\
\mathrm{n}=32\end{array}$ & $\begin{array}{c}\text { Group P } \\
\mathrm{n}=32\end{array}$ & P-Value \\
\hline Age (months) & $28.8 \pm 14.3$ & $30.9 \pm 13.4$ & $0.5^{*}$ \\
Height (cm) & $96.1 \pm 9.8$ & $96.9 \pm 7.4$ & $0.7^{*}$ \\
Weight (kg) & $15.1 \pm 4.8$ & $15.2 \pm 4.1$ & $0.9^{*}$ \\
Duration of Surgery (minutes) & $42.1 \pm 6.8$ & $41.3 \pm 6.9$ & $0.6^{*}$ \\
Gender & & & \\
Male & $30(93.7 \%)$ & $25(78.1 \%)$ & $0.18 \dagger$ \\
Female & $2(6.3 \%)$ & $7(21.9 \%)$ & \\
\hline
\end{tabular}

*Independent; t test used; tfisher exact test used.

Group 1: 
Table-2: Comparison of analgesic requirement between groups.

\begin{tabular}{|c|c|c|c|}
\hline $\begin{array}{l}\text { Analgesic requirement } \\
\text { with respect to time }\end{array}$ & $\begin{array}{c}\text { Group D } \\
n=32\end{array}$ & $\begin{array}{c}\text { Group } P \\
n=32\end{array}$ & P-Value \\
\hline At Recovery Room (Arrival) & $3(9.4 \%)$ & $23(71.9 \%)$ & $<0.000$ \\
\hline 30 minutes & $0(0 \%)$ & $4(12.5 \%)$ & 0.03 \\
\hline 1 hour & $2(6.3 \%)$ & $4(12.5 \%)$ & 0.4 \\
\hline 2 hours & $2(6.3 \%)$ & $8(25 \%)$ & 0.04 \\
\hline 3 hours & $0(0 \%)$ & $1(3.1 \%)$ & 0.9 \\
\hline 4 hours & $0(0 \%)$ & $0(0 \%)$ & - \\
\hline
\end{tabular}

Chi-square test and fisher exact test used.

higher mean pain scores compared to group $D(p<0.05)$, with a higher requirement for analgesia. The requirement for pain medication was also significantly higher in group $P$ at 30 minutes, with $4(12.5 \%)$ patients requiring analgesia in group $P$ compared to none in group $D$ $(p<0.05)$. At two hours, analgesic requirement was again significantly higher in group $P$ compared to group $D$ $(p=0.04)$, but the analgesic requirement was similar in the two groups at three and four hours postoperatively (Table-2; Figure).

\section{Discussion}

The results showed significantly lower pain scores in dexamethasone group compared to placebo group in the recovery room, and the finding is comparable with literature ${ }^{14}$ that studied the effect of IV dexamethasone with caudal analgesia in children aged 1-5 years in the postoperative period following orchidopexy. It found that a significantly lesser number of patients required rescue fentanyl in the dexamethasone group (7.9\% vs. $38.5 \%$ ) in PACU and they also required lesser paracetamol $(23.7 \%$ vs. $64.1 \%)$. It concluded that IV dexamethasone, when used along with caudal block, increases the efficacy of postoperative analgesia and also prolongs the analgesia. The effect of steroids in improving recovery profile in children after tonsillectomy was studied by Steward et al. who concluded that postoperative pain was improved in children receiving dexamethasone. ${ }^{15}$

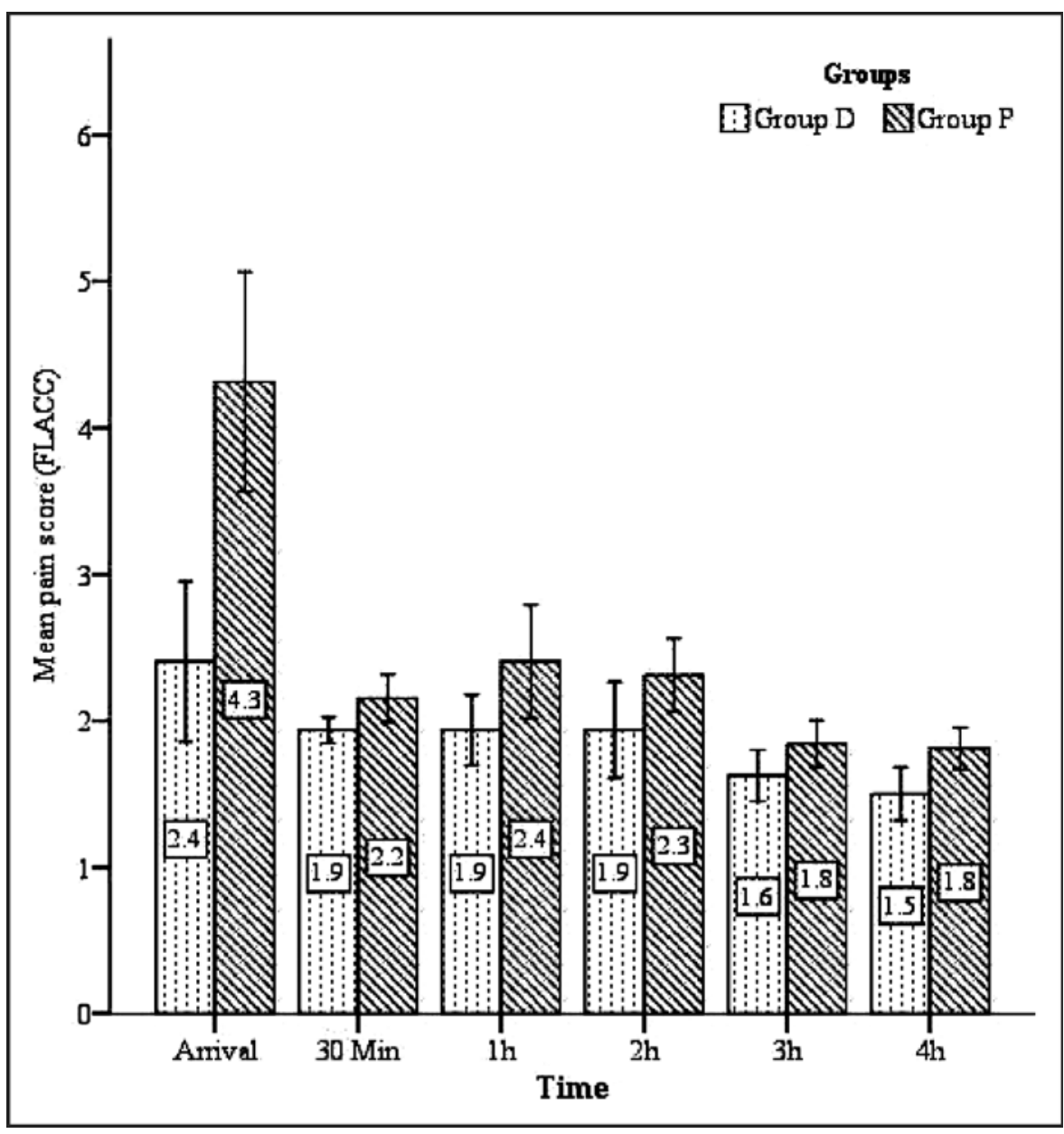

Figure: Mean pain score between groups with respect to time.
Overall effectiveness of postoperative pain relief is highly influenced by pain management in the immediate postoperative period. Close pain assessment and management during this period allows for timely discharge after daycare surgeries on regular simple analgesics and better patient and parent satisfaction. ${ }^{15}$ In the current study, 27 patients required rescue analgesia with pethidine in the placebo group in the first 30 minutes after surgery. In one study, dexamethasone group had lower postoperative pain scores and time for first need for oral paracetamol was also significantly longer in this group. ${ }^{14}$

Significant difference was not present in pain scores and the requirement for analgesic medications between the two groups at one hour and four hours postoperatively in the current study. Administration of rescue analgesia in recovery room is the probable reason for the similar pain profile seen in the two groups in the subsequent pain assessments. Again, two hours after surgery, 8 
patients required rescue analgesia in the placebo group compared to 2 in dexamethasone group. After effective pain relief in all patients in the first two hours postoperatively, the pain scores and the analgesic requirement remained similar in the two groups.

Some studies on adult patients have demonstrated analgesic efficacy of dexamethasone. A double-blind RCT studied the effect of single $8 \mathrm{mg}$ dose of dexamethasone on postoperative nausea, pain and vocal function after thyroidectomy compared to placebo. ${ }^{8}$ Postoperative pain was noted up to 48 hours with visual analogue scale (VAS). Also, there was significant reduction in pain scores in the dexamethasone group and requirement of rescue analgesia was also decreased compared to the control group. 8

A study evaluated the analgesic requirement with dexamethasone in patients scheduled for dental surgery in a randomised, double-blind study. It administered different doses of dexamethasone $(4,8$ or $16 \mathrm{mg})$ at the completion of surgery. There was a decreased postoperative requirement for rescue analgesia after the administration of $8 \mathrm{mg}$ and $16 \mathrm{mg}$ dexamethasone compared to placebo or $4 \mathrm{mg}$ dexamethasone. ${ }^{7}$ The study did not mention what adverse effects were found with higher doses. Another study compared the effect of a preoperative IV dose of dexamethasone on postoperative pain and other variables like emesis and haemorrhage compared to placebo, ${ }^{16}$ and reported that pain control was significantly better in dexamethasone group.

The limitation of the current study is that pain scores were followed for four hours postoperatively. Followup for a longer period would have further highlighted the analgesic effects of dexamethasone once the effect of caudal had worn off. However, all patients were day-care cases and were discharged within 6 hours of surgery, and logistics and financial constraints prevented telephonic follow-up. For similar reasons we were not able to assess our patients for side effects. An earlier study ${ }^{14}$ found that there were no adverse effects associated with one single dose of $0.5 \mathrm{mg} / \mathrm{kg}$ dexamethasone, thus making it a favourable choice for day-care orchidopexy in children. The main strength of our study is that bias and confounders were controlled by the use of a single, clear objective along with well-defined and measureable outcome variables. The well-defined inclusion and exclusion criteria further limited any bias or confounders, and the scientifically pre-calculated sample size provided strength to the study sample.
Further multicentre studies focussing on other variables, including safety, efficacy and adverse effects, associated with dexamethasone when used in children are recommended.

\section{Conclusion}

The analgesic effect of dexamethasone, when used along with caudal analgesia in day-care inguinal hernia repair, was commendable in the early postoperative period.

Limitation: This trial was not registered with a trial registry service because registration was not mandatory at the authors' institution (Aga Khan University) when the study was conducted in 2016.

\section{Disclaimer: None.}

\section{Conflict of Interest: None.}

\section{Source of Funding: None.}

\section{References}

1. Viitanen $H$, Tuominen $N$, Vääräniemi $H$, Nikanne $E$, Annila P. Analgesic efficacy of rectal acetaminophen and ibuprofen alone or in combination for paediatric day case adenoidectomy. $\mathrm{Br}$ J Anaesth. 2003; 91:363-7.

2. Gupta RW, Mehta A, Wali D, Gupta SD. Post-operative analgesia in children: caudal block with bupivacaine, rectal diclofenac and combination of both. J Anaesth Clin Pharmacol. 2008; 24:321-4.

3. Pyati S, Gan TJ. Perioperative pain management. CNS Drugs. 2007; 21:185-211.

4. Lee JU, Enkhtuvshin S, Ariuntungalag M, Odgerel B, Burmaa S, Ganbold L. Pain management in pediatric day surgery patients at The Maternal and Child Medical Research Center in Mongolia. Korean J Anesthesiol. 2010; 58:272.

5. Silvani P, Camporesi A, Agostino MR, Salvo I. Caudal anesthesia in pediatrics: an update. Minerva Anestesiologica. 2006; 72:453-9.

6. Boettger MK, Weber K, Gajda M, Bräuer R, Schaible HG. Spinally applied ketamine or morphine attenuate peripheral inflammation and hyperalgesia in acute and chronic phases of experimental arthritis. Brain Behav Immun. 2010; 24:474-85.

7. Numazaki M, Fujii Y. Reduction of postoperative emetic episodes and analgesic requirements with dexamethasone in patients scheduled for dental surgery. J Clinical Anesth. 2005; 17:182-6.

8. Worni $M$, Schudel HH, Seifert E, Inglin R, Hagemann M, Vorburger $\mathrm{SA}$, et al. Randomized controlled trial on single dose steroid before thyroidectomy for benign disease to improve postoperative nausea, pain, and vocal function. Ann Surg. 2008; 248:1060-6.

9. Hong JY, Han SW, Kim WO, Kim EJ, Kil HK. Effect of dexamethasone in combination with caudal analgesia on postoperative pain control in day-case paediatric orchiopexy. $\mathrm{Br} J$ Anaesth. 2010; 105:506-10.

10. Arbi MS, Izaham A, Kamaruzaman E, Zainuddin K, Ismail H, Manap NA. Intravenous dexamethasone in combination with caudal block prolongs postoperative analgesia in pediatric daycare surgery. Middle East J Anesthesiol. 2015; 23:177-83.

11. Shirazi M, Mahmoudi H, Nasihatkon B, Ghaffaripour S, Eslahi A. Efficacy of dexamethasone on postoperative analgesia in children undergoing hypospadias repair. Pak J Med Sci. 2016; 32:125-9. 
12. Taheri $\mathrm{R}$, Shayeghi $\mathrm{S}$, Razavi SS, Sadeghi A, Ghabili K, Ghojazadeh M, et al. Efficacy of bupivacaine-neostigmine and bupivacaine-tramadol in caudal block in pediatric inguinal herniorrhaphy. Paediatr Anaesth. 2010; 20:866-72.

13. Bringuier S, Picot MC, Dadure C, Rochette A, Raux O, Boulhais M, et al. A prospective comparison of post-surgical behavioral pain scales in preschoolers highlighting the risk of false evaluations. Pain. 2009; 145:60-8.

14. Kim J, Hong J, Song Y, Kil H. Effect of Intravenous Dexamethasone with Caudal Block on Analgesia after Pediatric Orchiopexy. [Online] 2011 [Cited 2011 Jan 01].
Available

from:

URL

http://www.asaabstracts.com/strands/asaabstracts/abstract.htm; jsessionid=8C80F81FD61B1BCF709DCC3215172466? year=2010\& index $=16 \&$ absnum $=549$.

15. Steward DL, Grisel J, Meinzen-Derr J. Steroids for improving recovery following tonsillectomy in children. Cochrane Database Syst Rev. 2011; 8:CD003997.

16. Khan MK, Manzoor T, Qayyum A. Effect of preoperative dexamethasone on postoperative pain, emesis and haemorrhage in tonsillectomy by dissection method. Pak Armed Forces Med J. $2011 ; 5: 61-5$. 